
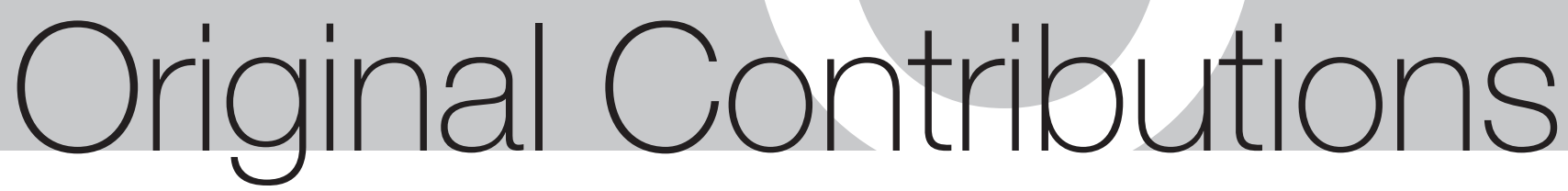

R. K. Wunderlich et al.: Thermophysical properties of the TiAl-2Cr-2Nb alloy in the liquid phase using the ISS-EML

Rainer K. Wunderlich ${ }^{\mathrm{a}}$, Markus Mohr ${ }^{\mathrm{b}}$, Yue Dong ${ }^{\mathrm{b}}$, Ulrike Hecht ${ }^{\mathrm{c}}$, Douglas M. Matson ${ }^{\mathrm{d}}$, Robert Hyers $^{\mathrm{e}}$, Gwendolyn Bracker ${ }^{\mathrm{e}}$, Jonghyun Lee ${ }^{\mathrm{f}}$, Stephan Schneider ${ }^{\mathrm{g}}$, Xiao Xiao ${ }^{\mathrm{g}}$, Hans-Jörg Fecht ${ }^{\mathrm{b}}$

${ }^{a}$ Metallurgy Europe, Ulm, Germany

${ }^{b}$ Institute of Functional Nanosystems, Ulm University, Ulm, Germany

${ }^{c}$ ACCESS e. V., Aachen, Germany

${ }^{\mathrm{d}}$ Department of Mechanical Engineering, Tufts University, Medford MA, USA

${ }^{\mathrm{e} U n i v e r s i t y ~ o f ~ M a s s a c h u s e t t s, ~ A m h e r s t ~ M A, ~ U S A ~}$

fDepartment of Mechanical Engineering, Iowa State University, Ames, IA, USA

'Institut für Materialphysik im Weltraum, Deutsches Zentrum für Luft- und Raumfahrt Cologne, Germany

\title{
Thermophysical properties of the TiAl-2Cr-2Nb alloy in the liquid phase measured with an electromagnetic levitation device on board the International Space Station, ISS-EML
}

\begin{abstract}
Thermophysical properties of the $\gamma$-TiAl alloy Ti$48 \mathrm{Al}-2 \mathrm{Cr}-2 \mathrm{Ni}$ in the liquid phase were investigated with a containerless electromagnetic processing device on board the International Space Station. Containerless processing is warranted by the high liquidus temperature $T_{\text {liq }}=1776 \mathrm{~K}$ and the high dissolution reactivity in the liquid phase. Thermophysical properties investigated include the surface tension and viscosity, density, specific heat capacity and the electrical resistivity. The experiments were supported by magnetohydrodynamic fluid flow calculations. The Ti48Al-2Cr-2Ni alloy could be stably processed over extended times in the stable and undercooled liquid phase and exhibited an exceptional degree of undercooling before solidification. Experimental processes and thermophysical properties so obtained will be described. The experiments demonstrate
\end{abstract}

the broad experimental capabilities of the electromagnetic processing facility on the International Space Station for thermophysical investigations in the liquid phase of metallic alloys not achievable by other methods.

Keywords: $\gamma$-TiAl alloys; Thermophysical properties; Liquid phase; Electromagnetic levitation; Microgravity processing

\section{Introduction}

Gamma Titanium-Aluminides ( $\gamma$-TiAls) are advanced structural materials for high temperature applications $[1,2] . \gamma$ TiAls are based on the Ti-50Al (in atomic per cent, at.\%) composition with additions of e.g. $\mathrm{Nb}, \mathrm{Ta}, \mathrm{Cr}$ and other refractory elements in the few at.\% range and of boron (B) 
and carbon $(\mathrm{C})$ in the 1 at.\% range to improve ductility and oxidation resistance. Composition, microstructure and mechanical properties are described in a series of review articles $[3,4]$. The main production route is casting $[5,6]$ with additive manufacturing becoming of increased importance [7]. Application of the various liquid processing techniques is supported by numerical modelling $[8,9]$ which requires accurate values of the relevant thermophysical properties in the liquid phase as input parameters. $\gamma$-TiAls have liquidus temperatures in the range of $T_{\mathrm{liq}}=(1790 \pm 40) \mathrm{K}$ and exhibit a high chemical reactivity in the liquid phase which makes thermophysical property measurement with conventional equipment difficult if not impossible.

$\gamma$-TiAls exhibit a complex microstructure based on a mixture of the hexagonal $\mathrm{Ti}_{3} \mathrm{Al}$ phase and the nearly cubic $\gamma$ $\mathrm{Ti}_{50} \mathrm{Al}_{50}$ phase [10]. Because of the complex solidification behaviour, the phase diagram of Ti-Al was the subject of intense experimental and theoretical investigations $[11,12]$. A series of $\gamma$-TiAls containing, $\mathrm{Nb}$ and $\mathrm{Ta}$ (with $\mathrm{B}$ and $\mathrm{C}$ ) as the minor alloying elements was investigated in the framework of the European FP6 research project IMPRESS including thermophysical property measurement in the stable liquid and high temperature solid phase $[13,14,15]$. Nucleation sequences were investigated by in-situ X-ray diffraction on electromagnetically levitated specimen $[16,17]$.

Because of the inherent difficulties of thermophysical property measurements with conventional methods, special techniques such as pulse heating [18] and containerless electromagnetic levitation (eml) [19] were applied for thermophysical property measurement in the liquid phase. Short duration microgravity processing with an eml on board a parabolic flight airplane was applied for the measurement of the surface tension and viscosity of a series of $\gamma$-TiAl alloys [20]. The available temperature range and times for liquid phase processing were limited to about ten seconds and did not allow for investigations of the specific heat capacity and of the viscosity with high accuracy. Consequently, an eml was installed on the International Space Station, the ISSEML, allowing extended processing of metallic melts for thermophysical property measurements [21, 22].

The extended processing time and the more quiescent operating conditions on the ISS allowed for a multitude of thermophysical property measurements of liquid metallic alloys over a larger temperature range and with higher accuracy than possible on board parabolic flights. This pertains in particular to measurement of the specific heat capacity and investigations of the effect of em stirring on nucleation not possible on board parabolic flights. Moreover, the analytical capabilities and measurement accuracy available with the ISS-EML allow application of magneto hydrodynamic (MHD) modelling and comparison with experimental results.

The present contribution describes the application of the ISS-EML to the measurement of a multitude of thermophysical properties of an industrial $\mathrm{Ti}-\mathrm{Al}$ alloy. The experiments were performed in the framework of an international collaboration between scientific groups supported by the European Space Agency ESA and national space agencies including DLR and NASA.

\section{Experimental procedures}

\subsection{Set up of the ISS-EML}

The setup of the eml on board the ISS and processing for thermophysical property measurements are described in detail elsewhere [23, 24]. In short: the ISS-EML consists of two connected ultra-high vacuum compatible steel chambers, the sample and process chamber. Both chambers are connected to a high-vacuum pumping unit and to a gas circulating system allowing operation under vacuum, argon and helium either in a stationary atmosphere or under adjustable gas flow. The gas circulation system contained a gas-cleaning unit with a nominal oxygen and $\mathrm{H}_{2} \mathrm{O}$ purity of $1 \mathrm{ppb}$.

Figure 1 shows a photograph of the open process chamber before assembly. The induction coil for combined induction heating and positioning [25] is shown in the centre. The induction coil is connected via high vacuum compatible rffeedthroughs to a radio frequency (rf-) heating and a rf-positioning generator operating at frequencies of 370 and $150 \mathrm{kHz}$, respectively. The inductive coupling between the current induced in the sample and the current in the induction coils can be used for the inductive measurement of the electrical resistivity and diameter of the specimen [26]. For the inductive measurements, a high sensitivity measurement device, the sample coupling electronics (SCE), was integrated in the rf-heater oscillating circuit [27]. The data acquisition and control system of the ISS-EML allows for the high precision measurement of the rf-heater and -positioner oscillating circuit voltage, current, their phase shift and frequency.

The sample shape was recorded with two digital cameras. The axial camera, with a frame rate of $150 \mathrm{fps}$ (frames per second), was directed along the axis of the induction coil. A pyrometer with a sampling rate of $100 \mathrm{~Hz}$ for temperature measurement was integrated into the axial camera. The radial camera, with frame rates from 30 to $30000 \mathrm{fps}$,

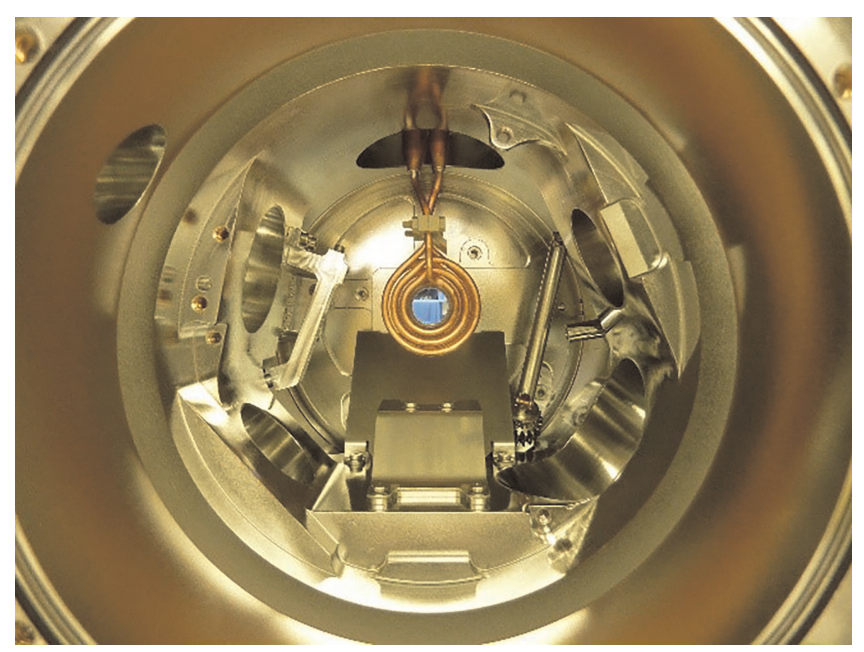

Fig. 1. Top view of the ISS-EML process chamber. The induction coil for heating and positioning is shown in the centre. The rf-feedthroughs for heating and positioning are located above the induction coil. Photograph with curtesy of Dr. W. Soellner, Airbus DS. 
was directed perpendicular in the equatorial plane of the sample. Both cameras were used for the detection of surface oscillations and sample observation for safe processing. The high frame rate of the radial camera was used for the recording of the propagation of solidification fronts.

The digital video images, pyrometer signal, rf-heater and positioner oscillating circuit data and a wealth of other data were transferred to an on board data acquisition and control system from which they could be downloaded for further analysis.

The sample chamber is flanged to the bottom of the process chamber. It holds 18 samples positioned on a sample wheel. Each sample is contained in its own sample holder with either a ceramic cup or a metallic cage structure on top. For processing, a sample holder is transferred from the sample wheel into the center of the induction coil.

\subsection{Sample material and preparation}

The sample material of industrial quality was provided by ACCESS e.V. For the preparation of the flight samples appropriate weight pieces to give an approx. $6.5 \mathrm{~mm}$ diameter spherical sample were cut. Pieces were cast in an arcmelter in a water-cooled $\mathrm{Cu}$ mould to a spherical form by the suction technique. The flight sample mass was $m=0.5528 \mathrm{~g}$ and average diameter $d_{\mathrm{av}}=6.44 \mathrm{~mm}$. Following casting the sample was transferred and stored in a glove box with high purity Ar. Integration into the ISS-EML was performed in a glove box at the facility developer [28] without breach of vacuum conditions. The oxygen concentration was measured on spare samples with the LECO hot gas extraction method as $400 \pm 20 \mathrm{wt} \mathrm{ppm}$. For the preparation of the $\mu$-g experiments calorimetry and dilatometry in the solid phase were performed with standard high temperature thermoanalytic equipment. The liquidus temperature was obtained as $T_{\text {liq }}=1776 \mathrm{~K}$.

Measurements of sample material evaporation as a function of temperature in vacuum were performed at DLR Cologne. Results were corrected for processing in $360 \mathrm{mbar}$ Ar. From these data an algorithm was constructed which calculated the mass loss from the temperature-time in each processing cycle [29]. The mass loss over all cycles was obtained as $140 \mathrm{mg}$ corresponding to a relative mass loss of $0.25 \%$.

\subsection{Processing in the ISS-EML for thermophysical property measurement}

Processing in the ISS-EML is organized in cycles defined as starting with a solid sample at room temperature, heating in the solid phase, melting, heating into the liquid phase, processing for thermophysical property measurement and subsequent cooling to solidification. The temperature program is effected by a predefined sequence of control voltages of the rf-heating generator stored in the facility computer. If needed, the rf-heater and positioner voltages and camera settings could be changed by reprogramming from ground to optimize experiment performance. Depending on the property to be measured, cycles had a duration between about five and more than $20 \mathrm{~min}$. A typical experiment consisted of about 50 to 100 cycles. During processing in the liquid phase, the value of the rf-positioning field is adjusted to assure safe processing. All cycles were performed in a stationary $360 \mathrm{mbar} \mathrm{Ar}$ atmosphere. Between cycles the gas atmosphere was circulated through the gas-cleaning unit.

\subsection{Measurement of surface tension and viscosity}

Surface tension and viscosity were measured by the oscillation drop method. The application of this method in an eml under reduced gravity was pioneered by Egry [30] and in the meanwhile is well established. A typical temperature-
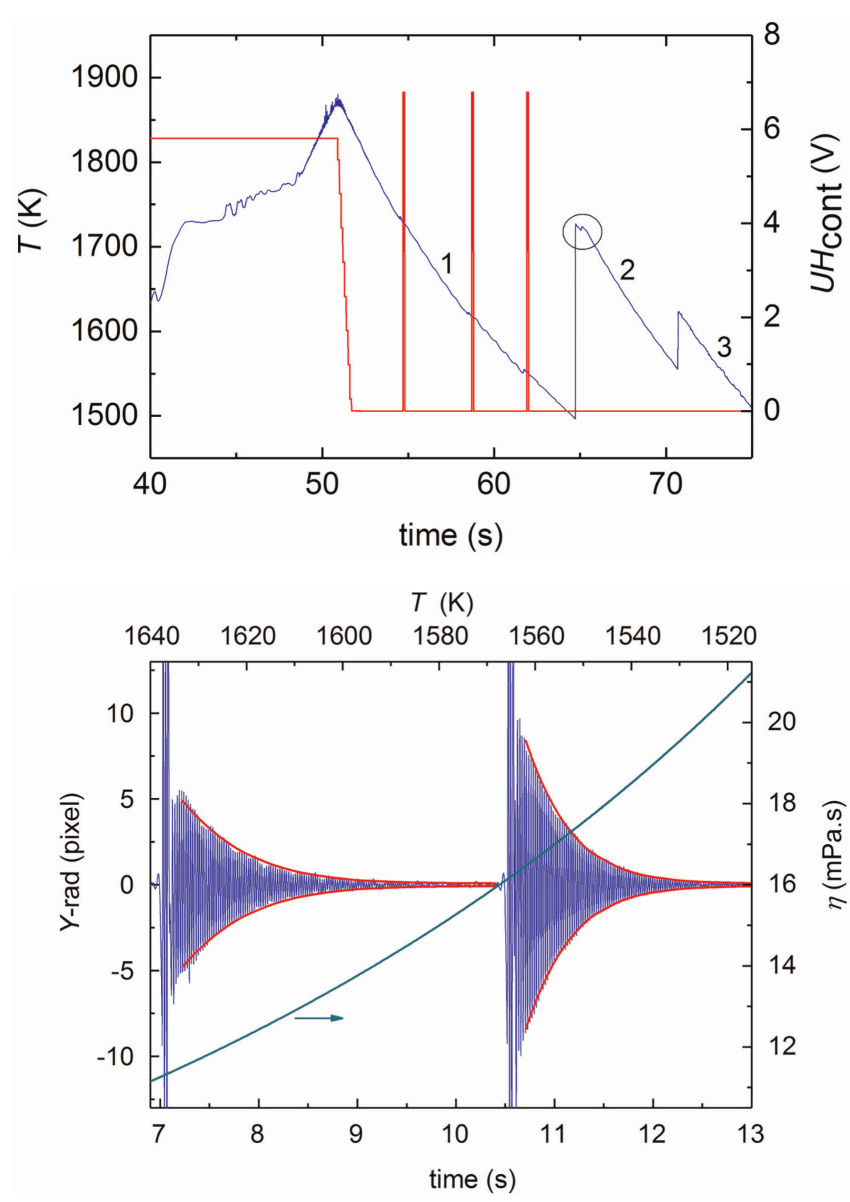

Fig. 2. (a) Upper pane: Temperature-time profile of a TiAl-2Cr-2Nb sample processed in the ISS-EML for surface tension and viscosity measurement by the oscillating drop method. Temperature is shown on the left hand ordinate, the rf-heater generator control voltage on the right-hand side. Numbers 1, 2,3 indicate different segments of the cooling curve for later reference. (b) Lower pane: Bottom and top $x$ axis show the time and correlated temperature, respectively. The left $y$-axis shows the variation of the sample radius in the $Y$-direction following the second and third excitation pulse shown in Fig. 2a as a function of time. The right $y$-axis shows the viscosity as a function of temperature resulting from the envelope fits to the $Y$-radius variation as a function of time, solid lines. 
time profile for surface tension and viscosity measurement is shown in Fig. 2a. A solid specimen is heated from ambient temperature to a pre-set temperature in the liquid phase followed by turning off the rf-heater. The onset of melting is indicated by the onset of the horizontal temperature halt at $T_{\text {ons }}=1730 \mathrm{~K}$. The emissivity of the pyrometer was adjusted that the end of melting identified as $T_{\text {liq }}$ corresponded to the liquidus temperature identified in ground based calorimetry.

In the nearly force free cooling phase, section 1, $100 \mathrm{~ms}$ duration rectangular rf-heater pulses were applied for the excitation of surface oscillations. The sample exhibited an undercooling of about $270 \mathrm{~K}$ followed by a double recalescence solidification pattern indicated by the circle in Fig. 2a. From the absence of a solidification plateau it is concluded that the sample solidified from an undercooling at or below the hypercooling limit.

For comparison, the $20 \mathrm{~s}$ of microgravity time available in a parabolic flight required fast heating and forced convective cooling resulting in large shape deformations at the beginning of the cooling phase and a high cooling rate of typically $70 \mathrm{~K} \mathrm{~s}^{-1}$ as compared to cooling rates of $23 \mathrm{~K} \mathrm{~s}^{-1}$ in the ISSEML with an in principle unlimited processing time resulting in a larger measurement temperature range and higher precision data.

Processing in the ISS-EML allowed for a variation of the rf-heater control voltage in the cooling phase to investigate the effect of induced em stirring and turbulence on the damping time constant of surface oscillations. Combined with the possibility of variation of the surface oscillation pulse height, magnetohydrodynamic phenomena such as non-linear effects in the oscillating drop method could be investigated [31]. This type of experiments were supported by magnetohydrodynamic model calculations [32,33].

Surface oscillations as a function of time were extracted from the digital image recordings with a dedicated software [34]. Figure $2 b$ shows the variation of the sample radius as a function of time following the second and third excitation pulse recorded with the radial camera with a frame rate of $400 \mathrm{fps}$. The signal was high pass Fourier filtered with a limit frequency of $v_{\mathrm{g}}=11.5 \mathrm{~Hz}$ leaving only the fast oscillations about the average sample diameter. In the particular cycle, the maximum sample shape deformation in the axial direction was $\leq 5 \%$.

The surface oscillation frequency as a function of temperature was obtained from fast Fourier transforms of consecutive time slices of the Y-radius variation. As a result, the centre frequency of the surface oscillations could be obtained with an accuracy better $0.5 \%$ covering the temperature range from 1843 to $1503 \mathrm{~K}$ from above $T_{\text {liq }}$ into the deeply undercooled liquid phase in a time of $\approx 12 \mathrm{~s}$, which is quite unique. The full red lines represent envelope fits to the variation of the surface oscillation amplitude as a function of time-temperature with a temperature dependent viscosity, see below. To our knowledge, this is the first measurement of the surface tension and viscosity of a highly reactive alloy extending over such a temperature range in a $40 \mathrm{~s}$ duration experiment.
The surface tension, $\sigma$, was evaluated from the surface oscillation frequency with the Rayleigh formula [35]:

$\sigma=\frac{3}{8} \pi M v_{\mathrm{R}}^{2}$

with $v_{\mathrm{R}}$ the surface oscillation frequency the so-called Rayleigh frequency and $M$ the sample mass. Application of this formula supposes small oscillation amplitudes and a force free sample. Regarding the latter, the effect of the positioning and small residual heating field in the cooling phase is corrected by the Cummings and Blackburn correction [36]:

$v_{\mathrm{R}}^{2}=v_{\mathrm{m}}^{2}-1.9 v_{\mathrm{tr}}^{2}-1.925 \times 10^{-4} v_{\mathrm{tr}}^{-2}\left(\mathrm{~b} \frac{g}{R}\right)^{2}$

$v_{\mathrm{m}}$ is the measured surface oscillation frequency, $R$ the sample radius, $g$ the earth gravitational acceleration and $b$ the actual microgravity level in units of $g$. $v_{\text {tr }}$ is the average translational frequency, of the sample center of mass in the potential well of the positioner field.

Typical values were $v_{\mathrm{m}}=35 \pm 2 \mathrm{~Hz}$ (here $\pm 2 \mathrm{~Hz}$ is the variation of $v_{\mathrm{m}}$ over the temperature range of the experiment) and $v_{\text {tr }}=2 \pm 0.5 \mathrm{~Hz}$ and $b=1.10^{-4}$ resulting in typical corrections of $v_{\mathrm{m}}{ }^{2}$ in the order of $-2 \%$.

The viscosity, $\eta$, was evaluated with the Lamb formula [37]

$\eta=\frac{3}{20 \pi} \frac{M}{R} \tau_{\mathrm{v}}^{-1}$

with $\tau_{\mathrm{v}}$ the viscous damping time of the surface oscillations. Faithful application of this formula requires a spherical equilibrium shape, small oscillation amplitudes and a purely exponential decay of the surface oscillation amplitude $A(t)=A_{0} \exp \left(-t / \tau_{v}\right)$. With regard to what is small there are widely different predictions by MHD model calculations of the dependence of the measured $\tau_{\mathrm{v}}$ on the amplitude of shape oscillations [38-40]. In a recent experimental investigation based on data obtained with Ni-based superalloys in the ISS-EML it was shown that oscillation amplitudes of $\leq 10 \%$ relative to the equilibrium sample radius did not have a measurable effect on $\tau_{\mathrm{v}}$ and, thus, on the viscosity evaluated with the Lamb formula in a similar range of viscosities [30]. This condition was met in all surface tension and viscosity cycles of this work.

The final viscosity as a function of temperature was evaluated as follows [31]: First, exponential envelopes were fitted to parts of surface oscillation decays shown in Fig. 2b following the second and third excitation pulse. The damping times so obtained are averages over temperature intervals of typically 30 to $50 \mathrm{~K}$. In the second step the corresponding viscosities were calculated with the Lamb formula and plotted in an Arrhenius diagram according to

$\ln \eta(T)=\ln \eta_{o}+\frac{\Delta E_{\mathrm{a}}}{k_{\mathrm{B}}} \frac{1}{T}$

from which the constants $\eta_{\mathrm{o}}$ and $\Delta E_{a}$ were evaluated. From these constants a temperature dependent viscosity $\eta(T)$ was calculated to obtain a temperature dependent surface 
oscillation damping time constant $\tau_{\mathrm{v}}(T)$ via Eq. (3). In the third step, exponential envelope fits with a temperature dependent $\tau_{\mathrm{v}}(T)$ and variation of $\eta_{\mathrm{o}}$ and $\Delta E_{a}$ were applied to obtain consistent fits to the variation of the surface oscillation amplitudes as a function of time-temperature in a number of cycles. The solid lines shown in Fig. $2 b$ represent such exponential envelope fits from which the final viscosity as a function of temperature was obtained. This viscosity is shown as a function of temperature on the right hand ordinate in Fig. 2b. From the envelope fits we claim a confidence level of $\leq \pm 2 \%$ for the viscosity. With this approach, surface oscillation amplitudes as a function of time-temperature from several cycles covering a temperature range of about $300 \mathrm{~K}$ could be very well fitted with a single set of $\Delta E_{\mathrm{a}}$ and $\eta_{\mathrm{o}}$ values independent of temperature and the degree of sample shape deformation. This type of analysis would not have been possible with parabolic flight experiments. To our knowledge, this is the largest temperature range, including the undercooled liquid phase, over which the viscosity of a $\gamma$-TiAl alloy has been measured.

\subsection{Measurement of density and electrical resistivity}

Similar temperature-time profiles as shown in Fig. 2a without the excitation pulses were applied for the measurement of the density in the liquid phase as a function of temperature. For the measurement of the electrical resistivity a small rf-heater bias voltage was applied.

In the optical method the density is evaluated from the digital image recordings of the radial camera. It required a calibration of the video images in terms of pixels vs. $\mathrm{cm}$ in the same temperature, radiance, range as applied in the measurements. The calibration was performed by processing a precision spherically milled and weighed solid $\mathrm{Zr}$ sample in the same temperature range. The sample diameter at room temperature was $d=6.7054 \pm 0.0002 \mathrm{~mm}$ and weight $m=1.0021 \pm 0.0002 \mathrm{~g}$. The $\mathrm{Zr}$ sample diameter as a function of temperature was calculated from the known density change at the $\alpha-\beta$ phase transition at $T=846^{\circ} \mathrm{C}$ and the well-known thermal expansion of solid $\mathrm{Zr}$ for $T>$ $846^{\circ} \mathrm{C}$. The edge detection algorithm provided a sub pixel resolution. With the sample diameter corresponding on average to $d_{\mathrm{av}}=201$ pixels, the accuracy of the diameter determination in the liquid phase is $<10^{-2}$.

The basic principle of the inductive measurement of the electrical resistivity, its implementation in the SCE device and a detailed analysis of the rf-heater and positioner oscillating circuits are given in Refs. [25, 26]. The sample represents an additional impedance in parallel to the induction coil of the rf-heater oscillating circuit. The impedance of the sample is given by its electrical resistivity and, for a spherical shape, its radius and a geometry factor containing the induction coil geometry. Its effect can be detected in the voltage, current, their phase shift and frequency of the rfheater oscillating circuit which are provided with high precision by the SCE. Thus, measurement of the electrical resistivity is preceded by an empty coil measurement and by a calibration run with the $\mathrm{Zr}$-sample in the solid phase with well-known electrical resistivity. An algorithm for the evaluation of the electrical resistivity was provided by G. Lohöfer from DLR Cologne.

2.6 Measurement of the specific heat capacity in the liquid phase

The specific heat capacity in the liquid phase was measured by non-contact modulation calorimetry. The method is based on modulated induction heating of a levitated specimen and measurement of the resulting temperature response by the pyrometer [41]. Basic principles and applications in an em-processing device under reduced gravity conditions are described in detail in Refs. [42, 43]. The method was recently applied in the ISS-EML to the Ti6Al-4 V wt.\% alloy in the liquid phase [44].

A typical temperature-time profile and the corresponding voltage in the rf-heater oscillating circuit are shown in Fig. 3a and b. Measurements were performed at four temperatures in the undercooled liquid phase over a time period
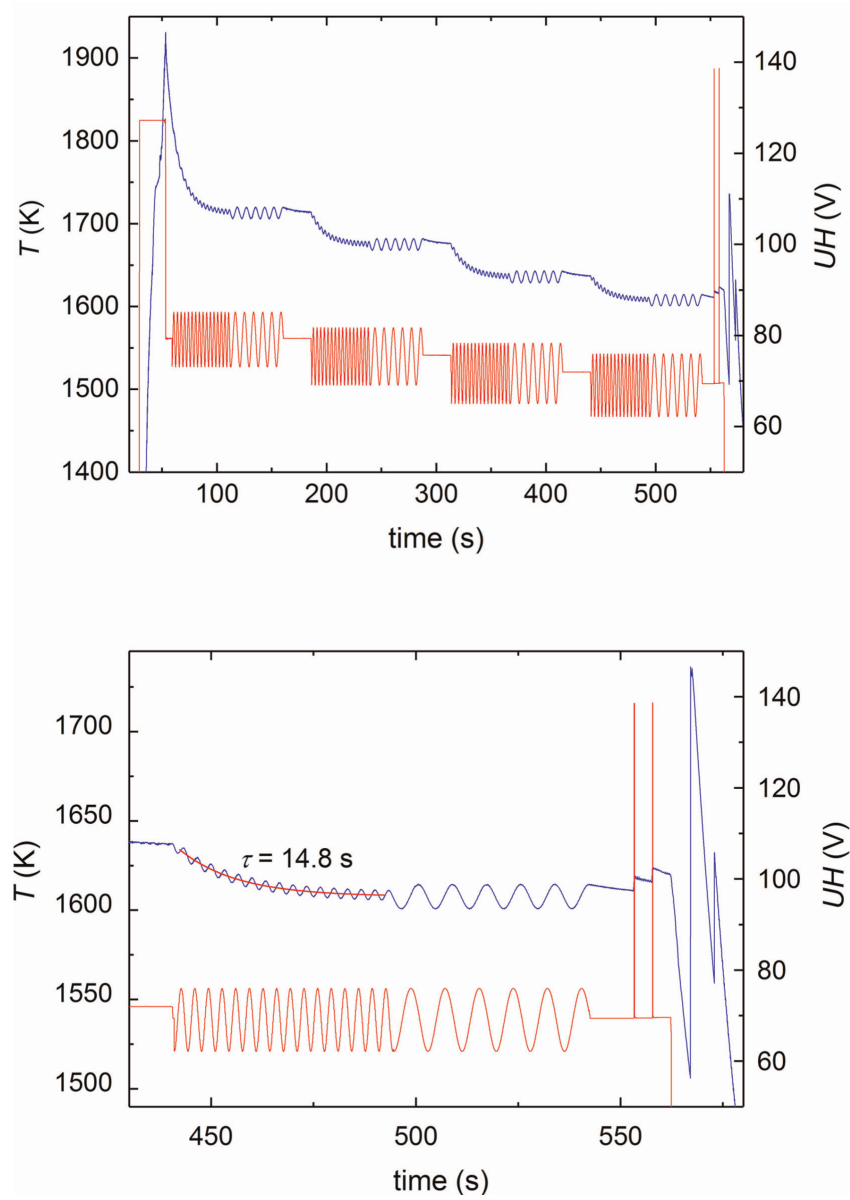

Fig. 3. (a) Upper pane: Processing of g-TiAl-2Cr-2Nb for specific heat capacity measurement. Temperature is shown on the right hand ordinate indicated by an arrow, the voltage in the rf-heater oscillating circuit on the left hand ordinate. (b) Lower pane: Detailed view of the last modulation step with evaluation of $\tau_{1}$, two surface excitation pulses, undercooling and recalescence. 
of about 10 min without solidification. After turning off the rf-heater, the sample undercooled further until solidification at an undercooling of about $270 \mathrm{~K}$.

Two modulation frequencies were applied. The smaller one, $\omega_{1}$, is chosen in the adiabatic regime where the effects of the finite thermal conductivity and heat loss to the environment on the amplitude of temperature modulation, $\Delta T_{\text {mod }}$, can be neglected on a confidence level of $\pm 2 \%$. The higher one, $\omega_{2}$, was chosen in a regime where the effect of the finite thermal conductivity should become apparent. The change of the average temperature as a function of time following a step function change in average heater power input is very well represented by an exponential $T_{\mathrm{av}}(t)=T_{o} \pm \Delta T \cdot\left[1-\exp \left(-t / \tau_{1}\right)\right]$ allowing evaluation of the external relaxation time $\tau_{1}$ which represents the time scale of heat loss to the environment as shown in Fig. $3 \mathrm{~b}$. $\tau_{1}$ has contributions from radiative heat loss and heat loss by conduction in the processing gas. The conductive contribution was evaluated by Lohöfer and Schneider [45]. Calibration experiments with a solid $\mathrm{Zr}$ sample were conducted in the same temperature range under vacuum and in Ar allowing separation of the radiative and conductive contributions to the external heat loss.

Following the last modulation step two surface oscillation excitation pulses were applied at constant average heating power input and temperature, as shown in Fig. 3b. This type of experiments were performed to investigate the influence of em stirring on the decay time of surface oscillations in comparison with that obtained in the standard surface tension and viscosity cycles and for comparison with the results of MHD model calculations. This demonstrates that quite complex experiments can be realized in a single processing cycle in the liquid phase. Such experiments would not be possible on shorter duration microgravity platforms or with a different processing method.

For a detailed presentation of non-contact modulation calorimetry we refer to the references given above. Only the basic elements will be given. The voltage in the rf-heater oscillating circuit, $U_{\text {osc }}$, is modulated with a frequency $\omega$ such that the inductive heating power input into the sample is given by:

$P(t)=P_{\mathrm{o}}+\Delta P_{\text {mod }}(\omega) \sin (\omega t)$

$P(t) \propto U_{\text {osc }}^{2}(t), I_{L}^{2}(t)$ where $I_{L}$ is the current in the induction coil. $P_{\mathrm{o}}$ represents the average heating power input resulting in the average sample temperature $T_{0}$. The modulated component, results in a modulated temperature response with amplitude $\Delta T_{\bmod }(\omega)$ which is related to $\Delta P_{\bmod }(\omega)$ as:

$\Delta T_{\text {mod }}(\omega)=\frac{\Delta P_{\text {mod }}(\omega)}{\omega C_{\mathrm{P}}} f\left(\omega, \tau_{1}, \tau_{2}\right)$

with $\mathrm{C}_{\mathrm{P}}$ the heat capacity of the sample. $f\left(\omega, \tau_{1}, \tau_{2}\right)$ is a correction function accounting for heat loss to the environment with the external relaxation time $\tau_{1}$ and for the finite thermal conductivity with relaxation time $\tau_{2} . f\left(\omega, \tau_{1}, \tau_{2}\right)$ is available in analytical form [43, 44]. For $\omega>\omega_{\mathrm{ad}}, \tau_{2}$ can be evaluated with reasonable accuracy from the phase shift $\Delta \varphi$ between
$\Delta T_{\bmod }(t)$ and $\Delta P_{\bmod }(t)$. The adiabatic modulation frequency $\omega_{\text {ad }}$ is characterized by $\Delta \varphi\left(\omega_{\mathrm{ad}}\right)=-90^{\circ}$ which is easily experimentally verified. For a large temperature range the rate of internal heat transport is much larger than the rate of external heat loss, i.e. $\tau_{2} \ll \tau_{1}$. In this case $\omega_{\mathrm{ad}}$ can be chosen such that $\tau_{2} \ll 1 / \omega_{\text {ad }} \ll \tau_{1}$ and

$\left|1-f\left(\omega_{\mathrm{ad}}, \tau_{1}, \tau_{2}\right)\right|<10^{-2}$

At temperatures $>1600 \mathrm{~K}$ the effect of $\tau_{1}$ on $f\left(\omega_{\mathrm{ad}}, \tau_{1}, \tau_{2}\right)$ can no longer be neglected. In the temperature range of the present experiment we obtained from the measured $\tau_{1}, \tau_{2}$ values $0.98 \leq f\left(\omega, \tau_{1}, \tau_{2}\right) \leq 0.99$ for the highest and lowest temperatures, respectively, with an accuracy $<1 \%$.

Quantification of Eq. (6) requires knowledge of $\Delta P_{\bmod }(\omega)$. It can be expressed as:

$\Delta P_{\text {mod }}(\omega)=G_{\mathrm{H}}(T) \cdot \Delta U_{\text {mod }}^{2}$

where $\Delta U_{\text {mod }}^{2}$ represents the amplitude squared of the modulated component of the voltage in the inductive branch of the rf-heating generator oscillating circuit. $\Delta U_{\bmod }^{2}$ is available with an accuracy $<0.2 \%$ in the dataset provided by the EML. $G_{H}$ represents the inductive coupling between the sample and the rf-heater oscillating circuit. It depends on the sample electrical resistivity, its radius, in general its shape and the geometry of the induction coil and, thus, depends on the measurement temperature.

For the scaling of $G_{H}\left(T_{\text {cal }}\right)$ from a calibration temperature $T_{\text {cal }}$ to the measurement temperature we applied the model of Fromm and Jähn [46] but more elaborate evaluations are available $[47,48] . T_{\text {cal }}$ is chosen in a phase with well-known $c_{\mathrm{P}}$, electrical resistivity $\rho(T)$ and sample radius $R(T)$. This phase is typically the solid phase of the same sample but can also be the solid phase of a different sample. In the present case modulation calibration experiments were performed with the precision ground solid $\mathrm{Zr}$ sample in the same temperature range as the $\gamma$-TiAl experiments.

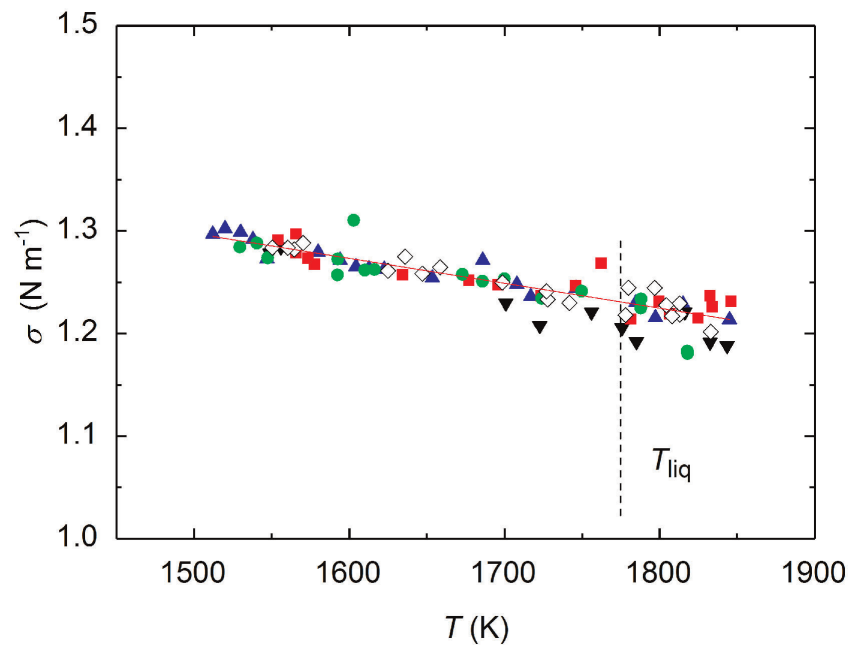

Fig. 4. Ti-48Al-2Cr-Ni. Surface tension as a function of temperature. Results compiled from five cycles. The vertical line indicates the liquidus temperature. 
In the model of Fromm and Jähn, $\Delta \mathrm{P}_{\text {mod }}$ is given by:

$\Delta P_{\text {mod }}(T)=3 \pi \rho(T) \cdot R(T) \cdot F(q) \cdot L_{\mathrm{H}} \cdot \Delta U_{\text {mod }}^{2}$

$F(q)$ is a function given explicitly [49] and $q$ is the ratio of the sample radius to the skin depth. $L_{\mathrm{H}}$ is a geometry factor entailing the induction coil geometry, sample radius and the inductivity and resistivity of the inductive branch of the rfheater oscillating circuit.

Equation (9) is sensitive to the effective sample radius, i.e. the radius in the equatorial plane perpendicular to the rf-field axis, which was evaluated from the optical recordings. At high temperature in the liquid phase this included deformation due to the magnetic field pressure and-or rotation.

\section{Results}

\subsection{Surface tension and viscosity}

Figure 4 shows the surface tension as a function of temperature obtained in five cycles. The data cover a temperature range of $340 \mathrm{~K}$. The data from the different cycles agree very well. The increased scatter for $T>1800 \mathrm{~K}$ is due to the initial shape deformation after the rf-heater was shut off at maximum temperature. The average of the data is well represented by a linear regression given by:

$$
\sigma(T)=\left[(1.24 \pm 0.015)-2.43 \cdot 10^{-4}(T-1776[\mathrm{~K}])\right] \mathrm{N} \mathrm{m}^{-1}
$$

with the precision of the slope $\leq 5 \%$.

Following the evaluation of the viscosity described in Section 2.4, the viscosity as a function of temperature is not given as a set of experimental data points but rather in terms of the Arrhenius parameters $\Delta E_{\mathrm{a}}$ and $\eta_{\mathrm{o}}$ which provided the best fits to the measured surface oscillation amplitude as a function of time-temperature as shown in Fig. 2b. The temperature range covered in this way ranged from 1520 to $1260^{\circ} \mathrm{C}$. The Arrhenius parameters are given in Table 1 . The value at $T_{\text {liq }}$ obtained in this work, $\eta\left(T_{\text {liq }}\right)=6.1 \pm 0.2$ mPa.s compares well with a value of $\eta\left(T_{\text {liq }}\right)=5.8 \pm 0.4$ $\mathrm{mPa}$.s obtained in a recent parabolic flight experiment [18] and also with a value of $\eta(1843 \mathrm{~K})=5.7 \pm 0.5 \mathrm{mPa}$.s obtained for the pure Ti-50 at.\% Al composition in a recent parabolic flight experiment by Wessing [49].

\subsection{Electrical resistivity and density in the liquid phase}

Figure 5 shows the electrical resistivity and diameter evaluated by the inductive method as a function of temperature. Sections indicated by 1, 2 and 3 in Figs. 2 a and 5 correspond to the same temperatures and phases. The large scatter of the data at the highest temperatures originates from sample deformations following turning off of the rf-heater generator. The values in the liquid phase, section 1 , cover the temperature range from $\mathrm{T}=1750$ to $1490 \mathrm{~K}$ and can be well represented by a linear regression given by:

$\rho(T)=\left(-3.13210^{-2}[K]+248.7\right) \mu \Omega \mathrm{cm}$

The negative slope is typical for high resistivity metallic materials. Following Ref. [27] the error of the electrical resistivity is estimated as $\leq 1 \%$. The rather high electrical resistivity in the liquid phase $\rho\left(T_{\text {liq }}\right)=187 \mu \Omega \mathrm{cm}$ agrees very well with a similar value obtained in pulse heating experiments by Cagran et al. [18] for the alloy Ti-44Al-8Nb-1B . The jump of $\rho(T)$ at $T=1490 \mathrm{~K}$ corresponds to the first recalescence step shown in Fig. 2a. It is supposed that the sample is crystalline thereafter.

The increase in density following the first recalescence, section 2 , is clearly apparent in the temperature-time profile, while the second recalescence with the solid-solid transformation and further cooling, section 3 , is not. The

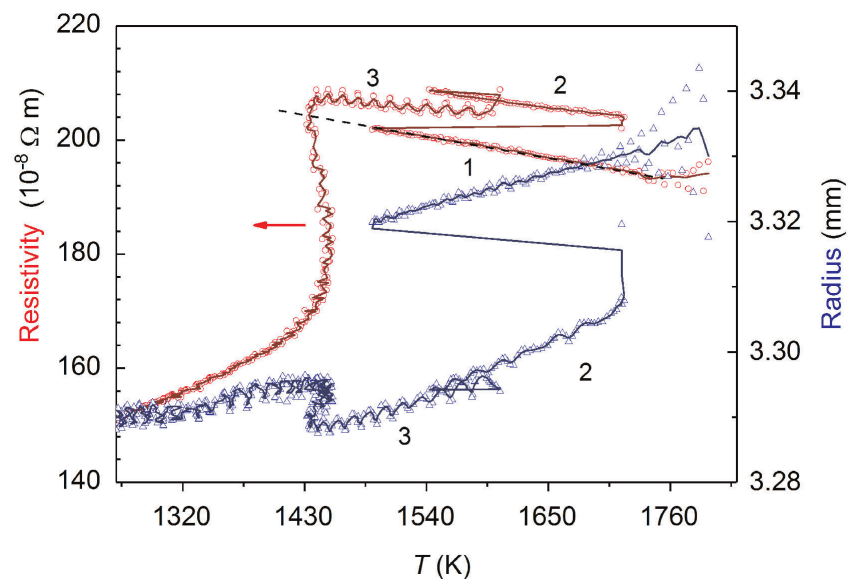

Fig. 5. TiAl-2Cr-2Nb. Electrical resistivity (red) and diameter (blue), as a function of temperature obtained with the inductive method shown on the left and right hand ordinate, respectively. The numbers correspond to the temperature segments indicated in Fig. 2a. Number 1 refers to the same segment of the electrical resistivity and of the diameter.

Table 1. Ti-48Al-2Cr-2Nb. Arrhenius parameters of the viscosity, viscosity at the liquidus temperature and at selected temperatures shown in the last two rows.

\begin{tabular}{|c|c|c|c|c|}
\hline$\eta_{0}(\mathrm{mPa} . \mathrm{s})$ & \multicolumn{2}{|c|}{$\Delta E_{\mathrm{a}}\left(\mathrm{eV}^{\mathrm{atom}}{ }^{-1}\right)$} & \multicolumn{2}{|c|}{$\eta\left(T_{\text {liq }}\right)$ (mPa.s) } \\
\hline $4.54 \times 10^{-3}$ & \multicolumn{2}{|c|}{1.10} & \multicolumn{2}{|c|}{$6.1 \pm 0.20$} \\
\hline$T(\mathrm{~K})$ & 1820 & 1773 & 6.93 & 1600 \\
$\eta$ (mPa.s) & 5.40 & 6.05 & \multicolumn{2}{|c|}{11.50} \\
\hline
\end{tabular}


density in the liquid phase at $T=1700 \mathrm{~K}$ is obtained as $\delta(1700 \mathrm{~K})=3.56 \mathrm{~g} \mathrm{~cm}^{-3}$. Comparison with a value of $\delta\left(T_{\mathrm{sol}}\right)=3.68 \mathrm{~g} \mathrm{~cm}^{-3}$ obtained with classical dilatometry results in a volume change on melting of $\approx+3 \%$ which is a very reasonable number. The sample radii measured by the optical method with the radial camera agree within $0.3 \%$ with those of the inductive method supporting the accuracy of the electrical resistivity values in the liquid phase.

For the 50-50 at.\% composition Wessing and Brillo obtained a value of $\delta(1700 \mathrm{~K})=3.38 \mathrm{~g} \mathrm{~cm}^{-3}$ in ground based em-levitation [50]. The increase in density is considered to result from the addition of the heavier elements $\mathrm{Cr}$ and $\mathrm{Nb}$.

\subsection{Specific heat capacity in the liquid phase}

The specific heat capacity as a function of temperature is shown in Fig. 6. The data cover the temperature range from 1550 to $1780 \mathrm{~K}$. From a multivariate analysis it is found that a variation of the sample radius by e.g. $5 \%$ had a much larger effect on the value of the specific heat capacity than a variation of the electrical resistivity by e.g. $-20 \%$ which resulted in a change of the specific heat capacity of just $-4 \%$. The specific heat capacity at the liquidus temperature was obtained as $c_{\mathrm{P}}\left(T_{\text {liq }}\right)=(1.08 \pm 0.05) \mathrm{J} \mathrm{K}^{-1} g^{-1}$ $\left(41.9 \mathrm{~J} \mathrm{~K}^{-1} \mathrm{~mol}^{-1}\right)$. The dashed line in Fig. 6 is a linear fit to $c_{\mathrm{P}}(T)$ in the indicated temperature range.

The accuracy of the specific heat capacity is primarily determined by the accuracy of the modulated component of the inductive heating power input $\Delta P_{\text {mod }}$ and $\Delta T_{\text {mod. }}$. At the calibration temperature $\Delta P_{\text {mod }}\left(T_{\text {cal }}\right)$ can be determined with an accuracy of $2 \%$. Given precisions $<1 \%$ for the electrical resistivity and radius, the scaling $\Delta P_{\text {mod }}\left(T_{\text {cal }}\right) \rightarrow \Delta P_{\text {mod }}\left(T_{\text {meas }}\right)$ can be performed with an accuracy of $2.2 \%$ from which an upper limit $\leq 4 \%$ for the accuracy of the $C_{\mathrm{p}}$ values is obtained.

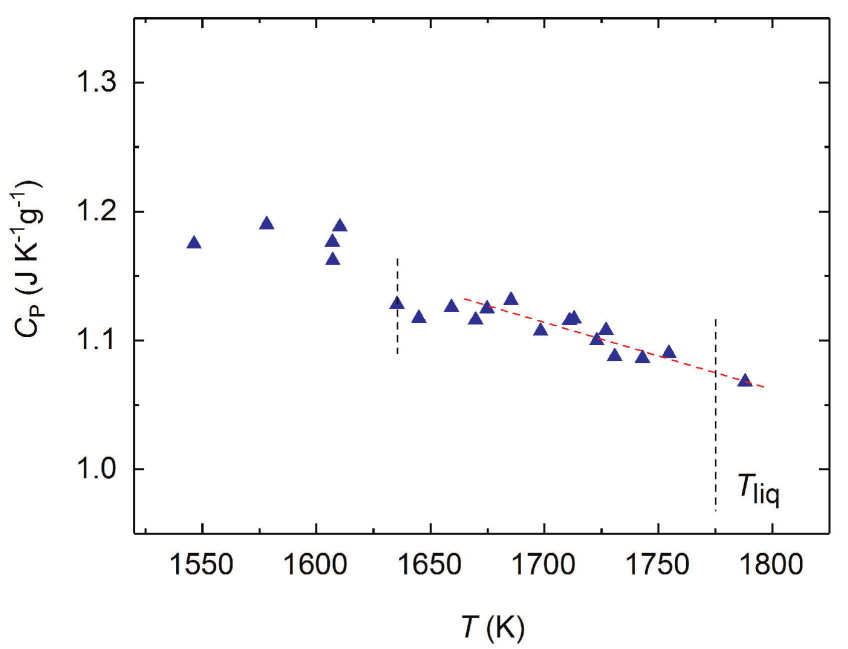

Fig. 6. TiAl-2Cr-2Nb. Specific heat capacity in the liquid phase evaluated with the Fromm and Jähn model for the em coupling. The horizontal dashed line indicates the typical error bar.

\subsection{Recalescence, phase selection and em stirring}

The first recalescence event consisted of two small peaks indicated by the circle in Fig. 2a. It is supposed that the sample was solid on further cooling, Section 2, followed by a second recalescence and further cooling, section 3 . Following the work of Shuleshova et al. $[16,17]$ on Ti$49.5 \mathrm{Al}-8 \mathrm{Nb}$ (at.\%) the double recalescence in the first main peak is interpreted as due to the formation of the bcc $\beta$ phase which quickly transforms to the hep $\alpha$-phase. This phase further undercools, section 2 , to the second recalescence event which is associated with the formation of the nearly cubic $\gamma$-phase.

In Fig. 7 we concentrate on the two smaller temperature rises in the first recalescence peak indicated by the circle in Fig. 2a. When the delay time between the two peaks is plotted as a function of temperature for tests conducted in argon it becomes apparent that, unlike what is observed in steel alloys [51, 52], stirring has no influence on the delay [53] for either transformation. This is shown in Fig. 7 where symbols represent different applied heater control voltages corresponding to different stirring levels. The slope of the line is negative $20.8 \pm 0.9 \mathrm{~K} \mathrm{~s}^{-1}$ which correlates well with the cooling rate seen in Fig. 2a which averages negative $21.0 \pm 7.3 \mathrm{~K} \mathrm{~s}^{-1}$ for tests conducted with no applied heating voltage. Since the slope is equivalent to the cooling rate it is apparent that the timing of the transformation is independent of both undercooling and stirring, possibly because any retained free energy drives recrystallization and is no longer available to drive the subsequent transformations. As to be expected, the few tests conducted in helium show a significantly enhanced cooling rate with shorter delay times again, independent of both undercooling and stirring. In an associated observation, during dynamic recrystallization of $\beta$ the temperature rise is independent of primary undercooling and shows a consistent value of $\Delta T=6.5 \pm 0.6 \mathrm{~K}$.

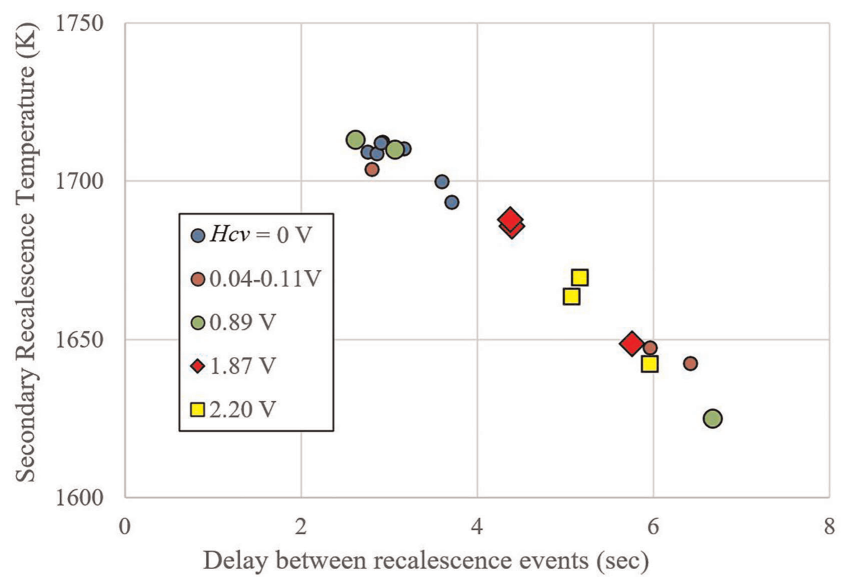

Fig. 7. TiAl-2Cr-2Nb. Transformation delay as a function of temperature and EM stirring. 


\section{Discussion}

The main emphasis of the current contribution is on the demonstration of the analytical capabilities of the ISS-EML for thermophysical property measurement in the liquid phase of metallic alloys applied to an industrial Ti-Al alloy and to present the thermophysical property values such obtained combined with MHD model calculations.

\subsection{Surface tension and viscosity}

The value of the surface tension at $T_{\text {liq }}$ obtained in this experiment, $\sigma\left(T_{\text {liq }}\right)=1.25 \mathrm{~N} \mathrm{~m}^{-1}$, is $2.5 \%$ larger than the value obtained in a recent parabolic flight experiment [20]. The alloy samples for both experiments were obtained from the same source. For comparison, in a recent series of ground based em levitation experiments, Wessing and Brillo [53] obtained a value of $\sigma\left(T_{\text {liq }}\right)=1.07 \mathrm{~N} \mathrm{~m}^{-1}$ for the generic Ti-50 at.\% Al composition. Given the very good reproducibility of the surface tension obtained in the different cycles and given that surface active adsorbants tend to reduce the value of the surface tension it is suggested to take the value given in Section 3.1 as a reference for the surface tension of this alloy.

The viscosity at $T_{\text {liq }}, \eta\left(T_{\text {liq }}\right)=6.10 \mathrm{mPa} . \mathrm{s}$, is larger than that obtained for ideal mixing applied to the Ti-50 at\% Al composition [20]. This is expected from the large negative heat of mixing of Ti-50 at.\% Al [12]. In Ref. [20] different semi-empirical models of the viscosity of the Ti-50 at.\% Al composition were tested against measured values of the Ti-48Al-2Cr-2Nb alloy. The best agreement was obtained with the Terzieff model [54] which predicted a $-12 \%$ lower viscosity while the Moelwyn-Hughes Model [55] gave a much higher viscosity. The same applies to the viscosity values obtained in this work. This result highlights the limited predictive quality of currently available viscosity models and the need for accurate measurements. As such, we recommend a value of $\eta\left(T_{\text {liq }}\right)=6.0 \pm 0.20 \mathrm{mPa}$.s as a reference value of the viscosity for this alloy.

In the calorimetry experiment shown in Fig. $3 b$ two surface oscillation excitation pulses were applied following the last modulation step. These experiments were performed to test the influence of em-induced fluid flow on the damping time of the surface oscillations. As a first result, the measured amplitude of surface oscillation as a function of timetemperature could perfectly well be represented with a temperature dependent viscosity calculated with the Arrhenius parameters given in Table 1. Apparently, for the particular value of the viscosity, $\eta(1617 \mathrm{~K})=12.4 \mathrm{mPa}$.s, electrical resistivity and current in the induction coil, turbulence is absent and the remaining laminar flow does not affect the damping of surface oscillations. Xiao et al. [56, 57] performed MHD model calculations over a wide range of material properties and operating conditions present in the various specimen processed in the ISS-EML [58]. For the conditions of the present experiment the maximum flow velocity was obtained as $19 \mathrm{~cm} \mathrm{~s}^{-1}$ giving a Reynolds number $R e \leq 380$. At this $R e$ number no turbulence is expected supporting the experimental result and the predictive quality of the applied MHD modelling. This result has practical implications for viscosity measurements in the undercooled liquid phase of metallic alloys with the oscillating drop method in that measurements could be performed with a finite heating power to reduce the cooling rate [in the liquid phase] to provide still more accurate viscosity values.

\subsection{Specific heat capacity in the liquid phase}

The value of the specific heat capacity at the liquidus temperature obtained in this work, agrees well with a value of $c_{\mathrm{P}}\left(T_{\text {liq }}\right)=0.99 \mathrm{~J} \mathrm{~K}^{-1} \mathrm{~g}^{-1}\left(38.4 \mathrm{~J} \mathrm{~K}^{-1} \mathrm{~mol}^{-1}\right)$ obtained from a recent calculation based on the CALPHAD method [59]. It also compares well with a value of $c_{\mathrm{P}}\left(T_{\text {liq }}\right)=$ $1.15 \mathrm{~J} \mathrm{~K}^{-1} \mathrm{~g}^{-1}\left(44.6 \mathrm{~J} \mathrm{~K}^{-1} \mathrm{~mol}^{-1}\right)$ for the alloy Ti-44Al$8 \mathrm{Nb}-1 \mathrm{~B}$ obtained in the pulse heating experiment by Cagran et al. [18]. In contrast, the value of the specific heat capacity in the liquid phase obtained in this work at $T=1700 \mathrm{~K}$, $c_{\mathrm{P}}(1700 \mathrm{~K})=1.12 \mathrm{~J} \mathrm{~K}^{-1} \mathrm{~g}^{-1}\left(43.5 \mathrm{~J} \mathrm{~mol}^{-1}\right)$ is considerably higher than values of $c_{\mathrm{P}}(1700 \mathrm{~K})=31.3 \mathrm{~J} \mathrm{~K}^{-1} \mathrm{~mol}^{-1}$ and $c_{\mathrm{P}}(1700 \mathrm{~K})=32.7 \mathrm{~J} \mathrm{~K}^{-1} \mathrm{~mol}^{-1}$ obtained for the Ti50 at.\% $\mathrm{Al}$ composition in a recent drop calorimetry experiment and a molecular dynamics simulation, respectively $[60,61]$. The latter values are close to the ideal mixing Neumann-Kopp value. Application of this rule is, however, difficult because it entails extrapolation of the elemental values over large temperature ranges. Our value of the specific heat capacity in the liquid phase as well as those of other authors [18] indicate a large deviation from ideality [12] similar to what is found for the viscosity.

\subsection{Magnetohydrodynamic calculations}

The same electromagnetic fields and induced currents that provide levitation and heating drive flow in the sample. That flow can provide advantages, such as by decreasing the effective Biot number through stirring, making the measurement of specific heat easier. The flow can also cause difficulties with other measurements, interfering with the measurement of thermal conductivity through convective heat transfer, or viscosity through turbulent damping.

Models of the magnetohydrodynamic (MHD) flow in the samples allow quantitative assessment of the various effects of flow on the different measurements. The critical input parameters are measured during the experiments themselves; including viscosity and electrical resistivity as described in $[62,63]$.

For ISS-EML experiments, models were built in ANSYS Fluent using the pressure-based solver. The models were 2-D axisymmetric, and the boundary conditions were symmetry on the axis and no traction on the free surface. The model was validated against the results of Ref. [4], where the flow on the surface of an EML sample was visualized and the model showed excellent agreement with the measured values with no adjustable parameters. More details of the model and additional modelling results are given in Ref. [33]. 


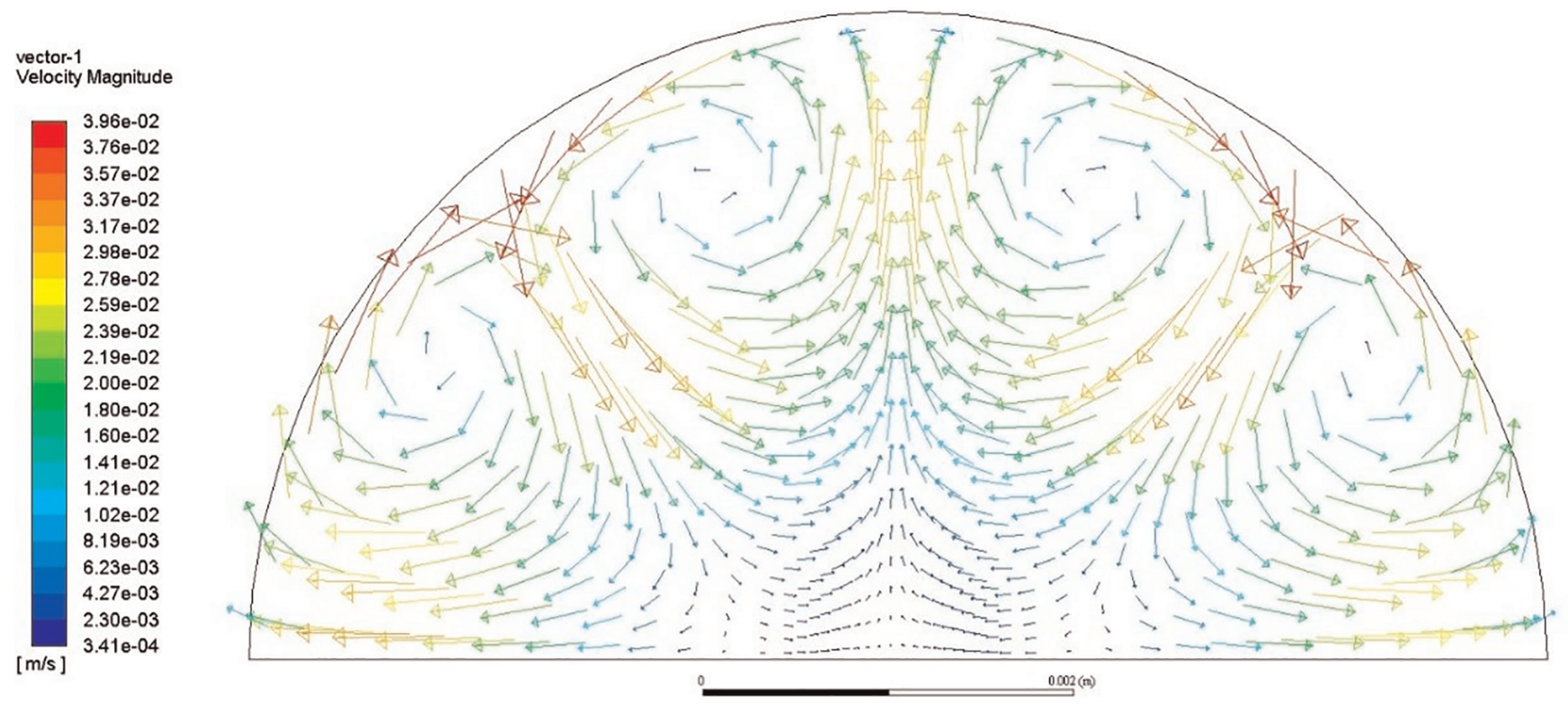

Fig. 8. Fluid flow pattern observed for laminar flow. Simulation run under conditions corresponding to $1710 \mathrm{~K}$ with a viscosity of $7.9 \mathrm{mPa}$.s. The induction coils are located left and right at an angle of $+25^{\circ}$ from the centre of the bottom horizontal line and there is symmetry with respect to the equatorial plane, bottom line. The arrows and length respectively indicate fluid flow direction and velocity.

Figure 8 shows the calculated flow for the conditions of $0.0 \mathrm{~V}$ heater, i.e. free cooling, and $7.2 \mathrm{~V}$ positioner at thermal equilibrium. The figure shows the fluid flow in the upper half of the sample in a cross-section cut from north to south pole defined by the direction of the em-field in the center of the induction coil. The temperature of the melt was $1710 \mathrm{~K}$. The electrical resistivity was approximated as $150 \mu \Omega \mathrm{cm}$. The viscosity was calculated using the Arrhenius parameters given in Table 1 as $\eta=7.9 \mathrm{mPa}$.s. The maximum velocity was obtained as $\approx 4 \mathrm{~cm} \mathrm{~s}^{-1}$ giving a max Reynolds number $R e \leq 80$. As a result, it can be assured that all surface tension and viscosity values presented are not affected by non-linear and turbulence effects.

\section{Summary and conclusions}

The electromagnetic levitation facility on board the ISS (ISSEML) was used for the measurement of a multitude of thermophysical properties of the alloy Ti-48Al-2Cr-2Nb in the liquid phase. The sample exhibited excellent positioning stability and could be processed over extended time periods in the stable and undercooled liquid phase at maximum temperatures of $1550{ }^{\circ} \mathrm{C}$. Thermophysical properties measured included the surface tension and viscosity, electrical resistivity and density, the specific heat capacity in the liquid phase, and investigations of the nucleation behaviour as a function of induced electromagnetic stirring. The experiments were supported by magnetohydrodynamic modelling of the fluid flow as a function of induced heating power. As a final result, besides providing a multitude of thermophysical property values in the liquid phase of an industrial alloy, this work also demonstrates the wide applicability of the ISS-EML for thermophysical investigations of metallic alloys in the liquid phase.
Funding: The work presented was supported by the Micro- Gravity User Support Center (MUSC) team at Deutsches Zentrum für Luft- und Raumfahrt in Cologne notably Drs. J. Schmitz, M. Engelhardt and J. Gegner. The support of the ISS-EML by Airbus DS in particular Dr. W. Soellner is gratefully acknowledged. UULM acknowledges the continued financial support by the German Space Agency DLR Bonn under contract numbers 50WM1170 and 50WM1759. The project was further funded in the framework of the ESA MAP Programme under contract number AO-99-022 (14306/01/NL/SH). Access e.V. gratefully acknowledges funding by BMWi/DLR through the GRADECET project under FKZ 50 WM 1443. R. Hyers acknowledges support in part by NASA under grant NNX16AB40G for this work. Work at Tufts University by D.M. Matson was sponsored by NASA grant 80NSSC 19 K0256.

\section{References}

[1] F. Appel, J.D.H. Paul, M. Oehring, in: Gamma Titanium Aluminide Alloys: Science and Technology, Wiley-VCH, Weinheim (2011), ISBN: 978-3-527-31525-3. DOI:10.1002/9783527636204

[2] H. Clemens, S. Mayer: Mater. High Temp. 23 (2016) 560. DOI:10.1080/09603409.2016.1163792

[3] R.M. Imayev, V.M. Imayev, M. Oehring, F. Appel: Intermetallics 15 (2007) 451 (2007). DOI:10.1016/j.intermet.2006.05.003

[4] K. Yang, Z.J. Yang, P. Deng: J. Mater. Eng. Perform. 28 (2019) 2271. DOI:10.1007/s11665-019-03970-y

[5] E. Schwaighofer, H. Clemens, S. Mayer, J. Lindemann' J. Klose, W. Smarsly, V. Güther: Intermetallics 44 (2014) 128. DOI:10.1016/j.intermet.2013.09.010

[6] J. Aguilara, A. Schievenbusch, O. Kättlitzc: Intermetallics 19 (2011) 757. DOI:10.1016/j.intermet.2010.11.014

[7] W. Chen, Z. Li, in: F. Froes and R. Boyer (Eds) Additive Manufacturing for the Aerospace Industry, Vol. 1, Elsevier, Amsterdam (2019) 235. eBook ISBN: 9780128140635.

[8] V. Bojarevics, K. Pericleous, R.A. Harding, M. Wickins: Met. Mater. Trans. B 35 (2004) 785. DOI:10.1007/s11663-004-0019-3

[9] R.A. Harding, M. Wickins, H. Wang, G. Djambazov, K. Pericleous: Intermetallics 19 (2011) 805. DOI:10.1016/j.intermet.2010.11.022 
[10] V. Imayev, T. Khismatullin, T. Oleneva, R. Imayev, R.Z. Valiev, R.K. Wunderlich, A. Minkow, U. Hecht, H.-J. Fecht: Adv. Eng. Mater. 10 (2008) 1095. DOI:10.1002/adem.200800159

[11] J.C. Schuster, M. Palm: J. Phase Equilib. Diffus. 27(2006) 255. DOI:10.1361/154770306X109809

[12] V.T. Witusiewicz, A.A. Bondar, U. Hecht, T.Ya.Velikanova: J. Alloy Compd. 644 (2015) 939.

DOI:10.1016/j.jallcom.2015.04.231

[13] D.J. Jarvis, D. Voss: Mater. Sci. Eng. A413 (2005) 583. DOI:10.1016/j.msea.2005.09.066

[14] K. Pericleous, V. Bojarevics, G. Djambazov, R.A. Harding, M. Wickins: Appl. Math. Modell. 30 (2006) 1262. DOI:10.1016/j.apm.2006.03.003

[15] I. Egry, R. Brooks, D. Holland-Moritz1, R. Novakovic, T. Matsushita, E. Ricci, S. Seetharaman, R. Wunderlich, in: M. Ninomi, S. Akiyama, M. Ikeda, M. Hagiwara, K. Maruyama (Eds.), Ti-2007 Science and Technology, The Japan Institute of Metals (2007) 671.

[16] O. Shuleshova, D. Holland-Moritz, H-G Lindenkreuz, W. Löser, B. Büchner: J. Phys. Conf. Ser. 144 (2009) 012118. DOI:10.1088/1742-6596/144/1/012118

[17] O. Shuleshova, T.G. Woodcock, H.G. Lindenkreuz, R. Hermann, W. Löser, B. Büchner: Acta Mater. 55 (2007) 681. DOI: org/ 10.1016/j.actamat.2006.08.058. DOI:10.1016/j.actamat.2006.08.058

[18] C. Cagran, B.Wilthan, G. Pottlacher, B. Roebuck, M.Wickins, R.A. Harding: Intermetallics 11 (2003) 1327. DOI:10.1016/S0966-9795(03)00175-4

[19] I. Egry, A. Diefenbach, W. Dreier, J. Piller: Int. J. Thermophys. 22 (2001) 569. DOI:10.1023/A:1010753805462

[20] R.K. Wunderlich, U. Hecht, F. Hediger, H.-J. Fecht: Adv. Eng. Mater. 20 (2018) 1800346. DOI:10.1002/adem.201800346

[21] D.M. Matson, M. Watanabe, G. Pottlacher, G.W. Lee, H.-J. Fecht: Int. J. Microg. Sci. Appl. 33 (2016) 330304. DOI:10.15011/ijmsa.33.330304

[22] H.-J. Fecht, R.K. Wunderlich: JOM 69 (2017) 1261. DOI:10.1007/s11837-017-2417-4

[23] A. Seidel, W. Soellner, C. Stenzel, in: International Symposium on Physical Sciences in Space 11-15 July 2011, Bonn, Germany, J. Phys. Conf. Ser., Vol.327 (2011) 012057. DOI:10.1088/1742-6596/327/1/012057

[24] A. Diefenbach, S. Schneider, T. Volkmann: A. Diefenbach, S. Schneider, T. Volkmann: Experiment Preparation and Performance for the Electromagnetic Levitator (EML) Onboard the International Space Station, IntechOpen (2020). 93470. DOI:10.5772/intechopen

[25] G. Lohoefer, J. Piller: AIAA 2002-0764 (2002).

[26] G. Lohöfer: Meas. Sci. Technol. 16 (2005) 417. DOI:10.1088/0957-0233/16/2/012

[27] G. Lohöfer: Rev. Sci. Instrum. 89 (2018) 124709. PMid:30599620; DOI:10.1063/1.5065482

[28] ISS-EML integration was performed at the facility developer AIRBUS DS, Friedrichshafen.

[29] J. Nawer, S. Gossé, D.M. Matson: JOM, 72 (2020) 3132. DOI:10.1007/s11837-020-04256-8

[30] I. Egry, G. Lohoefer, G. Jacobs: Phys. Rev. Lett. 75 (1995) 4043. PMid:10059800; DOI:10.1103/PhysRevLett.75.4043

[31] R.K. Wunderlich, M. Mohr: High Temp. - High Pressures 48 (2019) 253. DOI:10.32908/hthp.v48.648

[32] X. Xiao, R.W. Hyers, D.M. Matson: Int. J. Heat Mass Transf. 136 (2019) 531. DOI:10.1016/j.ijheatmasstransfer.2019.03.028

[33] G. Bracker, X. Xiao, J. Lee, D. Herlach, M. Rettenmayer, M. Reinartz, S. Burggraf, D.M. Matson, R. Hyers, in: G. Lambotte, J. Lee, A. Allanore, S. Wagstaff (Eds), Materials Processing Fundamentals 2019, Springer TMS-Series Cham Switzerland (2019). ISBN 13:978-3-030-05728-2.

[34] Image analysis software'TeVi' developed by SEA company on behalf of DLR Cologne.

[35] Lord Rayleigh: Proc. Royal Soc. 29 (1879) 7. DOI:10.1098/rspl.1879.0015
[36] D. Cummings, D. Blackburn: J. Fluid Mech. 224 (1991) 395. DOI: 10.1017/S0022112091001817

[37] H. Lamb: Hydrodynamincs, Cambridge University Press (1975) 450, ISBN: 052105515.

[38] S.R. Berry, R.W. Hyers, L.M. Racz, B. Abedian: Int. J. Thermophys. 26 (2005) 1565. DOI:10.1007/s10765-005-8104-7

[39] S. Spitans, A. Jakovics, E. Baake, B. Nacke: Met. Mater. Trans. B 44 (2013), 593. DOI:10.1007/s11663-013-9809-9

[40] J. Etay, P. Schetelat, B. Bardet, J. Priede, V. Bojarevics, K. Pericleous: High Temp. Mater. Proc. 27 (2008) 439. DOI: 10.1515/HTMP.2008.27.6.439

[41] H.-J. Fecht, W.L. Johnson: Rev. Sci. Instr. 62 (1991) 1299. DOI: $10.1063 / 1.1142488$

[42] R.K. Wunderlich, H.-J. Fecht: Meas. Sci. Technol. 16 (2005) 402. DOI: $10.1088 / 0957-0233 / 16 / 2 / 011$

[43] R.K. Wunderlich, H.-J. Fecht: Mater. Trans. 42 (2001) 565. DOI: $10.2320 /$ matertrans.42.565

[44] M. Mohr, R. Wunderlich, R. Novakovic, E. Ricci, H.-J. Fecht: Adv. Eng. Mat. 22 (2020) 2000169. DOI: $10.1002 /$ adem.202000169

[45] G. Lohöfer, S. Schneider: High Temp. - High Pressures 44 (2015) 147

[46] E. Fromm, H. Jähn: Z. Metallkd. 58 (1967) 366. DOI:10.1007/BF00409743

[47] G. Lohöfer: SIAM, J. Appl. Math. 49 (1989) 567. DOI: $10.1137 / 0149032$

[48] B.Q. Li: Int. J. Eng. Sci. 31 (1993) 201. DOI:10.1016/0020-7225(94)90041-8

[49] J. Wessing: PhD Thesis, Thermophysical properties of liquid AlTi alloys under the influence of oxygen, RWTH Aachen University (2018). https://publications.rwth-aachen.de/record/730189.

[50] J. Wessing, J. Brillo: Met. Mater. Trans. A 48 (2017) 868. DOI: $10.1007 / \mathrm{s} 11661-016-3886-8$

[51] D.M. Matson, X. Xiao, J.E. Rodriguez, J. Lee, R.W. Hyers, O. Shuleshova, I. Kaban, S. Schneider, C. Karrasch, S. Burggraff, R. Wunderlich, H.-J. Fecht: JOM 69 (2017) 1311. DOI:10.1007/s11837-017-2396-5

[52] D.M. Matson: Microgravity 4 (2018) 22. PMid:30480088; DOI: $10.1038 / \mathrm{s} 41526-018-0056-\mathrm{x}$

[53] D.M. Matson: JOM 72 (2020) 4109. DOI:10.1007/s11837-020-04375-2

[54] P. Terzieff: J. Alloys Compd. 453 (2008) 233. DOI:10.1016/j.jallcom.2006.11.074

[55] E.A. Moelwyn-Hughes: Physical Chemistry, Pergamon Oxford, 2nd Edition 1961.

[56] X. Xiao, R.W. Hyers, R.K. Wunderlich, H.-J. Fecht, D.M. Matson: Appl. Phys. Lett. 113 (2018) 011903. DOI: $10.1063 / 1.5039336$

[57] X. Xiao, J. Lee, R.W. Hyers, D.M. Matson: npj Microgravity 5 (2019) 7. PMid:30937361; DOI:10.1038/s41526-019-0067-2

[58] E.B. Baker, J. Nawer, X. Xiao, D.M. Matson: npj Microgravity 6 (2020) 9. PMid:32195320; DOI:10.1038/s41526-020-0099-7

[59] V. Vitusyvch, U. Hecht, ACCESS Aachen e. V., unpublished research (2020).

[60] K. Zhou, H.P. Wang, J. Chang, B. Wei: Appl. Phys. A103 (2011) 135. DOI:10.1007/s00339-016-9783-6

[61] X.J. Han, M. Chen, and Z.Y. Guo: Int. J. Thermophys. 26 (2005) 869. DOI: $10.1007 / \mathrm{s} 10765-005-5583-5$

[62] R.W. Hyers: Meas. Sci. Technol. 16 (2005) 394. DOI:10.1088/0957-0233/16/2/010

[63] R.W. Hyers, G. Trapaga, B. Abedian: Metall. Mater. Trans. B 34 (2003) 29. DOI:10.1007/s11663-003-0052-7

[64] J. Lee, D.M. Matson, S. Binder, M. Kolbe, D. Herlach, R.W. Hyers: Met. Mater. Trans. 45B, (2014) 1018. DOI:10.1007/s11663-013-9995-5

(Received March 2, 2021; accepted June 25, 2021) 


\section{Correspondence address}

Dr. R. Wunderlich

c/o

Prof. Dr. H.-J. Fecht

Institut für Funktionelle Nanosysteme

Universität Ulm

Albert-Einstein-Alle 47

D-89081 Ulm

Germany

Tel.: +497319503006

Fax: +49 731 502-5488

E-mail: rainer.kwunderlich@gmx.de

\section{Bibliography}

DOI 10.1515/ijmr-2021-8266

Int. J. Mater. Res. 112 (2021) 10; page 770-781

(C) 2021 Walter de Gruyter GmbH, Berlin/Boston, Germany

ISSN 1862-5282 · e-ISSN 2195-8556 